\title{
LINGUÍSTICA DA ENUNCIAÇÃO E DISTANCIAMENTO SOCIAL: UMA REFLEXÁO SOBRE PRESENÇA E AUSÊNCIA A PARTIR DO SISTEMA PRONOMINAL
}

\section{LINGUISTICS OF ENUNCIATION AND SOCIAL DISTANCING: A REFLECTION ON PRESENCE AND ABSENCE FROM THE PRONOMINAL SYSTEM}

\author{
Charlies Uilian de Campos Silva \\ Universidade Federal do Rio Grande do Sul, UFRGS, RS, Brasil \\ Instituto Federal do Rio Grande do Sul, IFRS Campus Restinga, RS, Brasil
}

\begin{abstract}
Resumo: Neste artigo, procuramos compreender como o cenário de distanciamento social está relacionado às reflexôes que formam a teoria enunciativa de Émile Benveniste. Com a suspensão de diversas atividades presencias, incluindo as aulas, vivemos um contexto de incertezas em relação ao processo pedagógico e nossos papéis enquanto professores e estudantes. Assim, partindo das reflexôes sobre pronomes e discutindo noçóes de pessoa, tempo, espaço e subjetividade, propomos uma perspectiva teórica capaz de instaurar uma dimensão ética na teoria enunciativa, buscando compreender como nossa relação com o outro no atual contexto de distanciamento social pode conduzir nossas palavras e atitudes nesse cenário pandêmico.
\end{abstract}

Palavras-chave: teoria da enunciação; sistema pronominal; distanciamento social; práticas escolares.

Abstract: In this article, we aim to understand how the scenario of social distancing is related to reflections that form Émile Benveniste's enunciation theory. With several activities suspended, including teaching, we live in a context of uncertainties regarding the pedagogical process and our roles as teachers and students. Thus, from the reflections on the pronouns and discussing notions of person, time, space and subjectivity, we propose a theoretical perspective to open an ethical dimension into Benveniste's theory, seeking to understand how our relationship with the other in the current context of social distancing can lead our words and attitudes in this pandemic scenario.

Keywords: enunciation theory; pronominal system; social distancing; school practices. 


\section{Introduçáo}

O ano é 2020 e as expectativas foram todas frustradas: com a chegada e a disseminação do vírus Sars-Cov-2, uma parcela significativa das atividades presenciais de nossa sociedade foi suspensa, tais como eventos artísticos, desportivos e culturais. Não é para menos: somamos, apenas no Brasil, mais de 100 mil mortes - e sem perspectiva de um desfecho para essa situação.

Esse cenário atípico, marcado sobretudo pelo distanciamento social e pela suspensão de uma série de atividades, força uma discussão absolutamente necessária e urgente sobre nossa relação com o outro e nossa participação na organização social. Nesse contexto, as instituições de ensino, não apenas do Brasil, mas de grande parte do planeta, tiveram suas aulas e demais atividades presenciais temporariamente suspensas. Enquanto algumas escolas buscam formas virtuais de retomar o calendário acadêmico e manter o ano letivo - tanto nas plataformas institucionais, como o Moodle, quanto em redes sociais diversas, como as lives do Instagram e do Facebook, além dos canais do Youtube -, outras instituiçóes pedagógicas enfrentam um contexto de contínua espera por um tratamento eficaz ou uma vacina para assegurar a volta às aulas com saúde para todos os agentes envolvidos no contexto educacional. Há também as escolas que buscam protocolos para uma volta presencial segura, mas pouco sucesso têm obtido nessa empreitada, visto o risco de contaminação viral.

Os obstáculos são distintos em cada cenário: no contexto de suspensão das aulas, conteúdos, atividades, calendários e avaliaçôes são postergados, o que pode influenciar de maneira negativa o processo pedagógico, acumulando e mesmo suspendendo a agenda escolar; já na hipótese de retomada presencial, há o alto risco de contágio dos agentes envolvidos no processo de ensino e aprendizagem, contabilizando, também, seguranças, servidores (geralmente terceirizados) dos setores de recepção e limpeza, prestadores de serviço, incluindo reparos elétricos, hidráulicos e oferta de transporte e alimentação; e, por fim, em uma situação de retomada virtual do calendário acadêmico, há um amplo debate sobre a qualidade da educaçáo ofertada e, acima de tudo, a surpreendente exclusáo digital de estudantes em pleno ano de 2020, quando internet de alta velocidade está disponível nas regiôes com maior poder aquisitivo, enquanto periferias e comunidades rurais carecem de acesso à rede virtual.

Ainda que estejamos presenciando um contexto de uso crescente das tecnologias digitais aplicadas ao ensino, é evidente que a educação remota 
ou à distância $(\mathrm{EaD})$ ainda enfrente muitos desafios. Segundo os dados mais recentes do Instituto Brasileiro de Geografia e Estatística (IBGE), coletados a partir da Pesquisa Nacional por Amostra de Domicílio Contínua (PNAD), $25,3 \%$ da população brasileira não possui acesso à internet - o que significa, na prática, que mais de 46 milhóes de brasileiros sofrem um processo de exclusão digital e, consequentemente, falta de acesso a informaçóes, plataformas, recursos, atividades, eventos e oportunidades veiculadas de forma virtual.

Também é significativo observar que a renda média das pessoas que não tem acesso à internet é de até um salário mínimo, o que implica que a exclusão digital está associada também à exclusão de renda. Dessa forma, precisamos considerar que "o nível do rendimento dos domicílios em área urbana suplanta o daqueles da área rural e essa diferença se reflete naturalmente nos indicadores desagregados por situação do domicílio" (IBGE, 2018, p. 27).

Nesse contexto de embate entre um protocolo recomendado e necessário de distanciamento social, justificado por medidas de saúde coletiva, e a desigualdade histórica e estrutural existente em nosso país, há, consequentemente, diversos processos de exclusão: social, tecnológica e financeira, por exemplo. Nesse sentido, a escola, o professor e o estudante se encontram em uma armadilha, em um paradoxo, pois toda alternativa possível também oferece desafios e é permeada por obstáculos e adversidades.

Além disso, precisamos considerar que escolas privadas e públicas possuem realidades distintas, com recursos e perfis estudantis absolutamente díspares. Ademais, também temos que pautar que a rede de ensino pública é tripartida: há instituiçôes federais, estaduais e municipais. Nesse sentido, a própria rede pública de ensino pode náo convergir em termos de datas e estratégias para retomada de atividades pedagógicas - tanto presencialmente, quanto no ambiente virtual.

Nesse cenário de incertezas, procuramos compreender quais relaçóes podemos estabelecer entre o contexto de distanciamento social, decorrente da pandemia de Covid-19, e o arcabouço teórico presente na Linguística da Enunciação, ancorado no trabalho do linguista Émile Benveniste (1902 - 1976), com especial destaque às reflexóes contidas nas obras Problemas de Linguística Geral I e Problemas de Linguística Geral II. Em síntese, nosso questionamento é: existe alguma contribuição teórica que os estudos enunciativos possam fazer no sentido de somar esforços para compreender o complexo contexto social, sanitário e educacional que vivemos? 
Nossa hipótese é de que haja, no conjunto de textos que compóem o quadro formal da Enunciação, elementos teóricos suficientes para questionarmos as noçôes de presença e ausência no atual cenário; da mesma forma, acreditamos que esse paradoxo da ausência-presença possa ser objeto teórico para os estudos enunciativos, que muito têm contribuído para analisar e compreender nossa relação com o mundo e com o outro - relação constituída por meio da linguagem.

Para tanto, faremos um breve panorama teórico que evidencia como o sistema pronominal, em seu caráter universal, ocupa um espaço especial na língua e instaura, invariavelmente, em todas as línguas conhecidas, uma dimensão ética da linguagem - dimensão fundada na nossa relação com o outro. Essa análise buscará indícios e elementos basilares nos seguintes textos: Estrutura das relaçóes de pessoa no verbo (1946), A natureza dos pronomes (1956), Da subjetividade na linguagem (1958), A linguagem e a experiência humana (1965) e $O$ aparelho formal da enunciação (1970).

Optamos por apresentar os textos em uma linha cronológica, respeitando a diacronia dos estudos de Émile Benveniste, tendo em vista que "não se pode ler na sincronia o que foi escrito em uma diacronia. Não cabe ler os textos de Benveniste como se fossem contemporâneos um do outro. Respeitar a cronologia dos textos é fundamental" (FLORES, 2012, p. 155). Além da própria distância temporal que separa essas reflexôes, que também pode ser considerada uma evidência do pensamento em contínua construção do linguista, pois o interesse pelos pronomes atravessa diferentes épocas da produção benvenistiana. Ademais, precisamos considerar que "[...] não há, de um lado, a linguagem, e, de outro, o homem, de um lado a sociedade e, de outro, a subjetividade: a linguagem, graças à utilizaçáo de um sistema linguístico, seja qual for, é a base que faz com que todo homem seja social e subjetivo"” (FENOGLIO, 2017, p. 213).

Contudo, antes de adentrarmos na discussão benvenistiana sobre os pronomes e o sistema pronominal, também necessitamos admitir que “[...] a leitura atenta dos textos dos PLG I e II náo permite, mesmo respeitada a cronologia dos textos, depreender um modelo acabado de análise, algo que, em linhas gerais, poderia ser chamado de uma metodologia" e que "[...] cada texto dos PLG encerra teorização e análise específicas” (FLORES, 2012, p. 154). Apesar de haver um diálogo e uma complementaridade entre os diferentes artigos de Benveniste e de propormos uma leitura de conjunto,

${ }^{1}$ No original: "Il n'y a pas d'un côté le langage, de l'autre l'homme, d'un côté la société, de l'autre la subjectivité: le langage, grâce à l'utilisation d'un système de langue, quel qu'il soit, est le liant qui fait que tout homme est social et subjectif". 
não podemos ignorar o fato de que cada texto tem sua discussão própria, sua terminologia específica e mesmo seu público-alvo, como é o caso, por exemplo, de A forma e o sentido na linguagem, que se trata, na verdade, de uma conferência proferida em um congresso de Filosofia.

Após, faremos uma análise de como nossa relação com o outro encontra, nesse período marcado pela suspensão da maioria das atividades presenciais, possibilidades e interditos para o contexto atípico de nossa rotina educacional. Em termos gerais, consideramos que, no conjunto de textos que compóem a reflexão benvenistiana sobre o sistema pronominal, podemos encontrar e realocar elementos teóricos que nos conduzam a uma dimensão ética de nossa relação com o outro, com o mundo, na e pela língua.

No atual cenário, considerando minha prática pedagógica enquanto professor de uma escola periférica, situada em um bairro historicamente marginalizado pelas políticas urbanas e pelo processo de estratificação social - mas também como linguista que se filia teoricamente ao campo dos estudos enunciativos -, preciso me questionar a respeito de como me coloco como eu perante um $t u$ muito específico e, ao mesmo tempo, genérico: meu estudante. Esse $t u$ expandido e vago, composto e pressuposto na minha relaçáo com o outro, convoca-me a me colocar como eu e me apropriar do exercício sempre contínuo da língua, do diálogo, da comunicação, do ser perante e somente perante outro ser.

\section{Em torno do pronome: constituiçáo e preceitos básicos da Teoria da Enunciação de Émile Benveniste}

A Teoria da Enunciação de Émile Benveniste, conforme a chamamos, tem, na verdade, sua origem em discussões de natureza linguística mais estrita. Em um primeiro momento, antes de falarmos de um quadro teórico para a enunciaçáo, discutiremos o funcionamento do sistema pronominal - observando que, mesmo em línguas de características e histórias completamente diferentes, o sistema pronominal apresenta uma estabilidade universal em seu funcionamento, tendo a noção de "pessoa" como o elemento basilar que inicia uma série de reflexóes sobre a relação entre o humano e a cultura.

Nesse sentido, cumpre destacarmos que a reflexão sobre os pronomes, conforme Benveniste a propóe, fundamenta-se na proposição de signos vazios, que são "[...] expressôes reflexivas, graças às quais (ou 'pelas quais') 
corpo e língua ligam-se instantaneamente num ponto incongruente e indissociável" (DUFOUR, 2000, p. 41, grifo do autor). Se há um fio que conecta uma discussão enunciativa e ética ao mesmo tempo, esse fio se apresenta nos signos vazios, que são um elemento intermediário entre a relação do próprio humano com sua língua.

Em Estrutura das relaçōes de pessoa no verbo (1946), Émile Benveniste chama nossa atenção para aspectos que indicam tanto a própria existência quanto o funcionamento da noçáo de pessoa. Essa reflexão é considerada essencial para se realizar a abertura do pensamento benvenistiano em relaçáo aos pronomes e aos signos vazios, pois a noçáo de pessoa, conforme é formulada no texto benvenistiano, não apenas reorganiza as noçôes intralinguísticas a respeito do funcionamento do sistema pronominal das diferentes línguas, assim como introduz justamente essa noção de pessoa como peça fundamental nesse sistema.

Nesse texto, Benveniste elabora uma proposição teórica ao opor as noçóes de pessoa e náo pessoa, destacando os traços distintivos entre a primeira, a segunda e a terceira pessoas do sistema pronominal. Para isso, o linguista utiliza exemplos de diversas línguas, alternando entre línguas muito conhecidas, como o inglês, línguas clássicas, como o grego, e línguas menos populares no debate linguístico ocidental, como o semítico, o coreano e o dravídico. Mais que isso, o autor propóe e fundamenta princípios teóricos para introduzir a noção de pessoa, evidenciando aspectos formais resultantes dessa discussão. Nesse sentido, cumpre destacarmos que "uma teoria linguística da pessoa verbal só pode constituir-se sobre a base das oposiçóes que diferenciam as pessoas, e se resumirá inteiramente na estrutura dessas oposiçôes" (BENVENISTE, 2005, p. 250).

Dessa forma, Benveniste observa que há, no interior da língua, compreendida como sistema, outro sistema: o dos signos vazios, tomado inicialmente como os pronomes e indicadores de subjetividade. Nesse sistema, a terceira pessoa (o ele) é justamente o ausente, aquele que não fala e, portanto, está situado fora da atividade enunciativa. Em outras palavras, podemos dizer que ele não se apropria da língua: ele é apenas objeto, tomado na fala de $e u$ e $t u$. Esse par, por sua vez, corresponde às pessoas do discurso:

[...] nas duas primeiras pessoas, há ao mesmo tempo uma pessoa implicada e um discurso sobre essa pessoa. Eu designa aquele que fala e implica ao mesmo tempo um enunciado sobre o "eu": dizendo $e u$, não posso deixar de falar de mim. Na segunda pessoa, "tu" é necessariamente designado por $e u$ e não pode ser pensado fora de uma situação proposta a partir do 
"eu"; e, ao mesmo tempo, eu enuncia algo como um predicado de "tu" (BENVENISTE, 2005, p. 250, grifo do autor).

Em síntese, podemos afirmar que $e u$ implica $t u$, a quem se dirige; contudo, $t u$, ao responder e se apropriar da língua, torna-se $e u$. Eu e $t u$ são, portanto, termos intercambiáveis, alternando-se e implicando-se continuamente. Mais do que um $e u$ e um $t u$, podemos afirmar que, no pensamento benvenistiano, há uma relação $e u-t u$ : existe uma autonomia relativa em cada termo, pois é na sua relação mútua que se instanciam efetivamente, possibilitando a interação. Já ele, o ausente, não é pessoa, não se apropria da língua, não tem voz: a terceira pessoa é o espaço da ausência.

Já em A natureza dos pronomes (1956), integrante de um conjunto de ensaios de diferentes autores reunidos em ocasião da celebraçáo do $60^{\circ}$ aniversário de Roman Jakobson, além de retomar a discussão iniciada dez anos antes em Estrutura das relaçóes de pessoa no verbo (FLORES, 2013), Benveniste adentra o universo das relaçóes estabelecidas entre as três pessoas do discurso. Cumpre destacar que, já no título, percebemos que há um pequeno ajuste teórico: saímos das estruturas do verbo e ingressamos na natureza dos pronomes.

Dito de outra forma, há uma pequena (embora significativa) mudança de perspectiva: a pessoa passa a ser observada centralmente no pronome - classe que interessa mais a Benveniste do que o verbo, pelo menos em termos de análise enunciativa -, além de as estruturas darem lugar a um termo que evoca determinado aspecto quase biológico e fisiológico de nossa condição falante, ao trazer à tona o termo natureza.

Essa natureza dos pronomes se apresenta em sua configuração triádica e opositiva, manifestando-se universalmente nas línguas. É, por isso, um aspecto de natureza linguística - e nela Benveniste (2005, p. 278, grifo do autor) situa $e u$ e $t u$ :

[...] qual é, portanto, a "realidade" à qual se refere $e u$ ou $t u$ ? Unicamente uma "realidade de discurso", que é coisa muito singular. $E u$ só pode definir-se em termos de "locuçáo", não em termos de objetos, como um signo nominal. Eu significa "a pessoa que enuncia a presente instância de discurso que contém $e u$ ”. Instância única por definição, é válida somente na sua unicidade.

Por sua vez, Da subjetividade na linguagem (1958) tematiza náo apenas a noção de pessoa, mas a própria subjetividade como um elemento linguístico. Nesse sentido, acreditamos que a subjetividade de que 
Benveniste fala é, na verdade, a relação que estabelecemos com o outro por meio da linguagem. Em termos sintéticos, a subjetividade é a relação mútua entre $e u$ e $t u$; configura-se, portanto, uma relação de intersubjetividade. A posição de $e u$, tomada como uma posição discursiva, implica, invariável e obrigatoriamente a presença de $t u$ :

[...] eu não emprego $e u$ a não ser dirigindo-me a alguém, que será na minha alocução um $t u$. Essa condição de diálogo é que é constitutiva da pessoa, pois implica em reciprocidade - que eu me torne $t u$ na alocução daquele que por sua vez se designa por eu (BENVENISTE, 2005, p. 286, grifo do autor).

Compreendemos, portanto, que, bem mais do que pronomes pessoais, $e u$ e $t u$ sáo espaços vazios que a língua oferece para que o falante possa adentrar a dimensão do discurso, tornando-se sujeito. Em outras palavras, o par eu-tu não corresponde a uma categoria pronominal ou lexical, mas sim a uma posição na língua: posiçáo que instaura $e u$ como aquele que toma a língua toda de uma vez só e a emprega na direção de $t u$. No universo eutu, há palavra e presença, configurando, assim, a subjetividade de que fala Benveniste; na dimensão do ele, há silêncio e ausência.

Há, dessa forma, uma dupla perspectiva de análise: de um lado, eu é uma categoria única, autorreferencial, preenchível por qualquer falante de qualquer língua; de outro, só há eu instaurado perante a presença reversível de um $t u$, situado no aqui e no agora. Nesse sentido, são oportunas as reflexóes de Ciulla (2018, p. 366): "Benveniste não se ocupa exatamente da dêixis, pelo menos não enquanto fenômeno de ostensão a objetos, mas da característica autorreferencial que está relacionada ao fenômeno". É, portanto, em uma relação contínua e complementar que existe a subjetividade, de acordo com Émile Benveniste. Dessa maneira, é preciso questionar, ainda e uma vez mais,

[...] a que, entáo, se refere o $e u$ ? A algo de muito singular, que é exclusivamente linguístico: eu se refere ao ato de discurso individual no qual é pronunciado, e lhe designa o locutor. É um termo que não pode ser identificado a não ser dentro do que, noutro passo, chamamos uma instância de discurso, e que só tem referência atual. A realidade à qual ele remete é a realidade do discurso. É na instância de discurso na qual $e u$ designa o locutor que este se enuncia como "sujeito". É portanto verdade ao pé da letra que o fundamento da subjetividade está no exercício da língua. Se quisermos refletir bem sobre isso, veremos que não há outro testemunho objetivo da identidade do sujeito que não seja o que ele dá assim, ele mesmo sobre si mesmo. A linguagem está 

toda designando-se como $e u$ (BENVENISTE, 2005, p. 288, grifo do autor).

Essa subjetividade, que é intersubjetividade, está relacionada ao conceito de ego (eu que diz eu), está intimamente associada ao conceito de pessoa em Benveniste e encontra na língua seu fundamento. A subjetividade benvenistiana, por assim dizer, dispóe de um sistema quádruplo (eu-tu-aquiagora) para se instaurar: é no tempo (agora) e no espaço (aqui) que uma pessoa $(e u)$ se dirige à outra $(t u)$. A subjetividade é marcada pelo presente (tempo) e pela presença (espaço), assim como corresponde a uma relação entre pessoas (eu e $t u$ ). Precisamos considerar, dessa forma, que "[...] a verdadeira realidade do tempo é a do instante; a duração é apenas uma construção, desprovida de realidade absoluta" (BACHELARD, 2007, p. 29).

Benveniste, ao introduzir o tempo e o espaço em sua reflexão, ressalta a necessidade dessas categorias para o quadro teórico da enunciação, pois são condiçôes imprescindíveis para instanciar $e u$ e $t u$ no mundo (discursivo). É táo somente no momento em que eu se propóe como sujeito - deixando de ser locutor - que o tempo e o espaço são instanciados. Em suma, o aqui e o agora são definidos em virtude do $\mathrm{eu}$. Assim, tempo e espaço formam, junto com a pessoa, as três bases axiomáticas que possibilitam a enunciação $\mathrm{e}$, consequentemente, nossa relação no mundo com o outro.

Por sua vez, A linguagem e a experiência humana (1965) é um texto presente nos Problemas de Linguistica Geral II (PLG II), diferentemente dos textos citados anteriormente, que integravam os Problemas de Linguistica Geral I (PLG I). Essa aparente separação, contudo, não representa um problema teórico ou metodológico para as análises benvenistianas; ao contrário de uma separaçáo, essa é, na verdade, uma evidência, um sinal (GINZSBURG, 1989) de como os temas são complementares e contínuos nas discussôes de Émile Benveniste. Há um continuum teórico que atravessa diferentes reflexôes e momentos da produção intelectual benvenistiana.

Em $A$ linguagem e a experiência humana, temos um texto que trata explicitamente da "[...] universalidade da experiência humana na linguagem. Náo há língua que possa ser concebida como tal sem apresentar a possibilidade de que nela, em seu interior, o homem possa se singularizar" (FLORES, 2013, p. 107-108). Nesse sentido, 
parecem corresponder a um modelo constante. As formas que revestem essas categorias são registradas e inventoriadas nas descriçōes, mas suas funções não aparecem claramente senão quando se as estuda no exercício da linguagem e na produção do discurso. Sáo categorias elementares, independentes de toda determinação cultural e nas quais vemos a experiência subjetiva dos sujeitos que se colocam e se situam na e pela linguagem (BENVENISTE, 2006, p. 68).

Assim, os conceitos de pessoa, tempo e espaço são universais nas diferentes línguas particulares, o que significa admitir que cada língua, de forma particular, necessita comportar essa tríade. É nessa travessia entre o particular e o geral que Benveniste se situa:

[...] o que eu não esperava e que então me impressionou nessa leitura contínua, era a alternância de dois tipos de textos distintos, que dependem de dois processos e duas retóricas: por um lado, análises de fenômenos linguísticos particulares, morfossintáticos ou lexicais, aos quais era aplicado cada vez o mesmo método: uma descriçấo minuciosa de uma estrutura particular, em uma ou várias línguas, concluindo-se por uma generalização com objetivo de explicação; como a descrição das relaçóes de pessoa (1946), da frase nominal (1950b), da voz média em relaçáo à voz ativa (1950a), da frase relativa (1957) etc. Por outro, textos completamente teóricos se apresentando, conforme o caso, como análise ou programas, de tom geralmente dogmático: eles enunciam uma série de afirmaçôes de âmbito geral, em uma argumentação que se quer estrita; tratam da linguística geral da qual fazem balanço ou traçam as tendências "atuais", depois, cada vez mais, da semiologia, como existe e como deve ser (NORMAND, 2009, p. $15)$.

Quando o locutor assume a posição eu, há, na realidade, uma experiência humana sempre nova e única na linguagem: "[...] desde que o pronome eu aparece num enunciado, evocando - explicitamente ou náo - o pronome tu para se opor conjuntamente a ele, uma experiência humana se instaura de novo e revela o instrumento linguístico que a funda" (BENVENISTE, 2006, p. 68, grifos do autor). Assim, a experiência humana na linguagem é sempre nova e possibilita nossas correlaçóes de subjetividade. A trajetória que vivenciamos diariamente só é possível porque somos seres de linguagem inseridos em uma sociedade de linguagem. É a linguagem o fio condutor que nos conecta e, paradoxalmente, nos separa, ao mesmo tempo, do outro; é por meio da linguagem que eu busca $t u$, mas também é nela que $e u$ está constituído e enclausurado enquanto $e u$.

Por fim, em $O$ aparelho formal da enunciação (1970) - texto 
encomendado pelo linguista Tzvetan Todorov em carta datada de 30 de setembro de 1968 -, Benveniste estabelece um quadro teórico que oferece uma síntese para as reflexôes enunciativas iniciadas décadas atrás com Estrutura das relaçóes de pessoa no verbo (1946). Esse, que foi o último artigo publicado pelo linguista sobre a temática enunciativa, "[...] condensa os mais de quarenta anos de reflexão linguística sobre a enunciação" (FLORES, 2013, p. 161).

Para Benveniste, a enunciação converte a língua em discurso, situando pessoa, tempo e espaço; é, dessa forma, um ato que ultrapassa os limites e as possibilidades da língua sistema (também conhecida como langue, em Saussure). Contudo, para que o falante tome a língua inteira e se proponha como $e u$, é necessário que, nas diferentes línguas, haja o compartilhamento de categorias universais; essas categorias, nas palavras de Émile Benveniste, correspondem ao que chamamos de aparelho formal da enunciação:

[...] o que em geral caracteriza a enunciação é a acentuação da relação discursiva com o parceiro, seja este real ou imaginado, individual ou coletivo. Esta característica coloca necessariamente o que se pode denominar o quadro figurativo da enunciação. Como forma de discurso, a enunciação coloca duas 'figuras' igualmente necessárias, uma, origem, a outra, fim da enunciação. É a estrutura do diálogo. Duas figuras na posição de parceiros são alternativamente protagonistas da enunciação. Este quadro é dado necessariamente com a definição da enunciaçâo (BENVENISTE, 2006, p. 86 , grifo do autor).

Percebemos, portanto, que a reflexão de natureza intralinguística iniciada na discussão sobre os pronomes começa a fundar uma teoria ampla sobre a linguagem, o humano e sua relação com o outro. Dessa maneira, se nossa subjetividade possui fundamentos linguísticos e se apresenta como uma intersubjetividade, é evidente que as reflexóes de Benveniste ultrapassam o escopo estritamente linguístico; merecem, por assim dizer, consideraçóes éticas, que fundamentem a perspectiva como o linguista situa a pessoa no mundo (tempo e espaço), isto é, como um ser em relação. Nesse sentido, relembramos a reflexão de Teixeira (2012): os pronomes abrem uma porta de entrada para uma teoria geral do humano na linguagem - não são apenas uma reflexão de natureza estritamente linguística. Há, na análise benvenistiana sobre o sistema pronominal, desdobramentos teóricos que nos conduzem a questóes sociais, éticas e antropológicas. 


\section{Distanciamento social e enunciação: quais são as implicaçóes éticas?}

Antes de conduzirmos o quadro teórico enunciativo para as questóes relativas ao distanciamento social e à suspensáo das atividades acadêmicas, é preciso admitir que as reflexôes que propomos baseiam-se, além dos próprios estudos linguísticos, sobretudo no escopo da Linguística da Enunciação, em minha prática pedagógica, que é também um elemento de subjetividade que perpassa minhas reflexóes como linguista. É, portanto, como professor e como linguista que me situo nesse debate; nesse sentido, minha trajetória em uma escola situada na periferia urbana é um elemento inerente às proposiçóes teóricas aqui apresentadas, pois vivencio em meu fazer pedagógico e testemunho como pesquisador o processo de exclusão digital existente em nossa sociedade.

Dessa forma, enquanto eu professor-pesquisador, preciso me questionar: quem é meu tu em sala de aula? Essa questáo, justamente por situar minha interlocução, é também uma questão ética: para quem me dirijo? A pessoa com quem falo é parte de minha constituição intersubjetiva; em suma, o outro é parte de mim. A ética que propomos em Benveniste é, em síntese, uma ética da intersubjetividade, demarcada pela relação que eu e $t u$ estabelecem por meio da linguagem, situadas no tempo (agora) e no espaço (aqui).

Em nosso entendimento, a enunciação e é uma atividade sempre nova, que engloba a língua toda; Benveniste (2006, p. 82) afirma que a enunciaçáo é "[...] este colocar em funcionamento a língua por um ato individual de utilização". Ressaltamos que, embora esse ato seja realizado por um indivíduo, não é um ato meramente individual, egóico e egocentrado, pois pressupóe sempre e invariavelmente o outro indivíduo (o $t u$ ) em sua alocução. Essa enunciação, entendida como uma atividade sempre nova, enfrenta, hoje, um cenário desconhecido, marcado tanto por expectativas quanto por desafios que se apresentam a professores e estudantes.

Se partirmos do pressuposto de que a enunciação estabelece uma relaçáo intersubjetiva entre $e u$ e $t u$, é evidente que precisamos considerar em nossa atividade enunciativa o $t u$ a quem nos dirigimos enquanto professores. Nesse sentido, precisamos, ainda, considerar as realidades sociais, as trajetórias de vida, as experiências subjetivas e únicas que cada indivíduo possui. Portanto, é necessário reconhecer que o professor (eu) tem em seu estudante um tu: é somente na relaçáo com o aluno que o professor pode se constituir, é apenas por meio da coexistência de dois (ou mais) universos 
subjetivos que podemos nos relacionar.

Vivemos, hoje, um contexto social singular que, por sua vez, singulariza nossas práticas. E, nesse cenário, somos convocados ao diálogo e ao posicionamento. Dessa forma, o professor, na dimensão ética que propomos - isto é, do eu que só existe em plena relação com o tu, partilhando os eixos tempo e espaço -, não pode transformar o estudante em ele, tirando-lhe o direito à fala, colocando uma ausência no espaço da presença.

As desigualdades sociais apenas tornam esse processo de diálogo e de uma ética relacional ainda mais complexo e difícil. Saber falar e ouvir é, bem mais que um ato puramente linguístico, uma atitude ética de nossa presença no mundo enquanto ser de linguagem. De um lado, temos situaçóes de escolas e estudante devidamente equipados para as possibilidades virtuais de ensino e, de outro, cenários de vulnerabilidades e exclusóes, cada vez mais acentuados, considerados os impactos sociais e econômicos implicados pelas próprias medidas de restriçáo, tais como informalidade e instabilidade laboral.

Embora reconheçamos numerosos aspectos positivos do trabalho remoto, como a própria retomadas das atividades pedagógicas e acadêmicas, incluindo os setores de pesquisa e extensão, além de atividades técnicoadministrativas, também é necessário pontuar que não vivemos uma cultura escolar plenamente habituada aos espaços virtuais. O ensino básico, hoje, é associado às atividades presenciais, apesar de crescer exponencialmente o uso de ferramentas e recursos tecnológicos que expandem nossas possibilidades de atuação.

Assim, temos um entrave: o retorno remoto às atividades, como vem sendo realizado em diversas instituiçôes de ensino - de todas as esferas - no país, por um lado, marca nossa presença, nossa participação, nossa constituição enquanto sujeitos na linguagem e por meio da linguagem; por outro lado, há ainda um grande número, tanto de instituiçôes quanto de estudantes, que não conseguem acessar e/ou utilizar satisfatoriamente os recursos educacionais virtuais. É evidente que essas ausências não são apenas números/estatísticas: são indivíduos que não puderam se propor como sujeitos na língua, como seres de linguagem, presentes e fazendo presença.

Nesse sentido, a enunciação nos ensina que não podemos ser $e u$ sem remetermos eticamente a um $t u$, sem nos dirigirmos de maneira responsiva ao outro que me constitui e que se constitui, por sua vez, também em mim. Não podemos, assim, reproduzir um cenário de desigualdades: a desigualdade social, atrelada à exclusão digital, não pode transformar tu 
em ele: cada estudante precisa ser um sujeito (de linguagem) nessa relação pedagógica e ética. Não há diálogo, não há presença quando silenciamos e excluímos pessoas que são, de forma sistemática, marginalizadas pela sociedade, sobretudo em um contexto de pandemia universal que afeta todos os setores sociais e econômicos. Esse cenário caótico, de incertezas e insegurança, não deve ser um pretexto para desconsiderarmos de nossa fala $\mathrm{e}$ de nossa perspectiva os estudantes menos privilegiados, que náo têm acesso à internet.

Considerando-se que a educação é direito de todos e dever do Estado, segundo nossa Constituição Federal, precisamos compreender que nossas palavras e nossos posicionamentos possuem um peso histórico e ético do qual não podemos, nunca, livrar-nos. É certo que as comunidades acadêmica e escolar deveráo encontrar formas alternativas na tentativa de recuperar o ano letivo e as atividades de ensino.

Da mesma forma, é inegável que esse cenário só faz evidenciar o abismo social que vivemos em nosso país, com desigualdade de renda e de oportunidades. É preciso tanto considerar as possibilidades de retomada de ensino para o estudante virtual, quanto pensar em alternativas pedagógicas para reincluir o estudante que está, hoje, totalmente atrelado ao ensino presencial.

Nossa trajetória no mundo é, no arcabouço teórico benvenistiano, um momento de encontro, de presença, de partilha de tempo e espaço. Embora Benveniste trate essas categorias como essencialmente linguísticas, é um ser corporificado, materializado, situado no tempo e no espaço que se propóe como sujeito linguístico $(e u)$. O locutor que faz sua passagem a sujeito na língua é, antes de tudo, um corpo materializado no mundo.

Assim, náo podemos ignorar o tempo e o espaço em que vivemos: um tempo de desencontro, um espaço permeado por ausências. Nosso diálogo presencial está temporariamente suspenso e toda tentativa de retorno às atividades acadêmicas e escolares precisa levar em consideração a ampla desigualdade social existente em nosso país. Ignorar o contexto multifacetado que compóem nossa tessitura social pode acarretar no silenciamento, no apagamento de diversos tus que náo poderão estar presentes no universo virtual.

A sala de aula, seja ela virtual ou presencial, consiste em um espaço de encontro simultâneo entre $e u$ e $t u$ : é nosso agir ético considerar as realidades, os desafios e as expectativas desse tu-estudante, que é para quem os esforços do eu-professor estão voltados. Essa possível conversão de $t u$ (presente) em 
ele (ausente) é um desafio que as diferentes instituiçóes de ensino terão de enfrentar nesse contexto atípico. Valorizar a importância da presença do tuestudante é, em última instância, reconhecer que a interação é um elemento imprescindível nas relaçôes pedagógicas, de forma específica, e nas relaçôes sociais, de forma geral.

\section{Conclusáo}

Concluímos, assim, que a enunciação tem seu tempo demarcado: situa-se sempre no presente atualizável e fugaz. Esse tempo, conforme o compreendemos, é o próprio presente do ser, do eu que toma a língua toda e de uma vez só, convertendo-se em sujeito na e pela língua. Assim, por um lado, percebemos que o presente consiste na medida temporal por excelência da enunciação - que é sempre atual e contemporânea - e, por outro, que o tempo do ser, assim como o tempo da enunciação, é o presente. Corpo e linguagem implicam-se.

O axioma parece ser simples: se não existimos fora da linguagem, não nos situamos jamais fora das categorias de tempo, pessoa e espaço. Somente no presente, somente no aqui e agora, existimos: esse é o eixo que separa nossa existência entre o que já foi e o que está por vir. Nada pode estar fora desse presente axial: é do presente que partimos, seja em direção ao passado, seja em direção ao futuro. Em suma, nosso tempo é hoje.

Dessa forma, o deslocamento teórico que propomos consiste em uma perspectiva de análise que busca compreender desafios, expectativas e realidades de nossa sociedade pandêmica, buscando respostas e soluçôes. Nosso agora virtual ainda não é a realidade em muitos aquis, geralmente, localidades periféricas e rurais que, estatisticamente, possuem menos acesso à internet e, consequentemente, vivenciam um processo sistêmico e igualmente pandêmico de exclusão digital.

Contudo, existem diversas plataformas e numerosos recursos que podem, de maneira segura, oferecer um espaço virtual para que eu e $t u$ se instanciem novamente, retomando o diálogo e o desenvolvimento das atividades acadêmicas e pedagógicas.

Quando chegará o tempo de tomarmos todos a língua inteira? Que possamos finalmente entender que cada eu presente é insubstituível e que, na nossa sociedade, não compartilhamos o mesmo tempo e espaço: enquanto muitas pessoas vivem na sociedade tecnológica e virtual, há inúmeras outras 
que não têm acesso à água potável e à rede de esgoto em suas residências.

É nesse cenário complexo que, enquanto linguistas e professores, posicionamo-nos e manifestamo-nos na e pela linguagem. Sempre e cada vez mais, precisamos lembrar e ressignificar uma máxima benvenistiana: "[...] bem antes de servir para comunicar, a linguagem serve para viver" (BENVENISTE, 2006, p. 222). Este artigo é um manifesto enunciativo pela educação brasileira e está comprometido com cada estudante - ausente e presente - de nossas salas de aula.

Não há como fugir de assumirmos uma posição ética na linguagem - e, portanto, no mundo. Tendo isso em vista, precisamos considerar que mesmo o silêncio e a ausência são significativos, pois mostram questôes que precisamos compreender in absentia. $\mathrm{O}$ fazer ético enunciativo é sempre um ato direcionado a outro ser, a um $t u$; a coexistência e o compartilhamento do tempo-espaço são aspectos de uma teoria não apenas linguística, mas também ética $e m$ e de Émile Benveniste.

\section{Referências}

BACHELARD, G. A intuiçáo do instante. Campinas: Verus, 2007. . Problemas de linguística geral I. Campinas: Pontes, 2005. Problemas de linguística geral II. Campinas: Pontes, 2006.

CIULlA, A. Sobre a definiçấo de dêixis a partir de "A natureza dos pronomes". Desenredo, Passo Fundo, v. 14, n. 3, p. 364-379, set./dez. 2018.

DUFOUR, D.-R. Os mistérios da trindade. Rio de Janeiro: Companhia de Freud, 2000.

FENOGLIO, I. La langue et l'écriture: un écart théorique entre Benveniste et Saussure. Revista do GELNE, Natal, v. 19, n. especial, p. 211-236, 2017. FLORES, V. N. Notas para uma (re)leitura da teoria enunciativa de Émile Benveniste. In: .; TEIXEIRA, M. (org.). O sentido na linguagem: uma homenagem à professora Leci Borges Barbisan. Porto Alegre: Edipucrs, 2012.

Parábola, 2013.

Introduçáo à teoria enunciativa de Benveniste. São Paulo: GINZBURG, C. Sinais - raízes de um paradigma indiciário. In: GINZBURG, C. (org.). Mitos, emblemas, sinais. São Paulo: Companhia 
das Letras, 1989. p. 143-275.

INSTITUTO BRASILEIRO DE GEOGRAFIA E ESTATÍSTICA (IBGE). Pesquisa Nacional por Amostra de Domicílio Contínua. Rio de Janeiro, 2018. Disponível em <https://www.ibge.gov.br/estatisticas/sociais/ habitacao $/ 17270$ pnadcontinua.html? edicao $=27138 \& \mathrm{t}=$ downloads $>$. Acesso em: 20 jul. 2020.

NORMAND, C. Leituras de Benveniste: algumas variantes sobre um itinerário demarcado. Letras de Hoje, Porto Alegre, v. 44, n. 1, p. 12-19, jan./mar. 2009.

TEIXEIRA, T. L. M. O estudo dos pronomes em Benveniste e o projeto de uma ciência geral do homem. Desenredo, Passo Fundo, v. 8, n. 1, p. 71-83, jan./jun. 2012. 